\title{
"Os tecidos da capulana": narrativas e imagens em torno dos cuidados e afetos
}

\author{
VERA FÁTIMA GASPARETTO iD \\ Universidade Federal de Santa Catarina | Florianópolis, SC, Brasil \\ gasparettovera@yahoo.com.br \\ MATEUs Almeida iD \\ Universidade Federal Fluminense | Niterói, RJ, Brasil \\ mateusalmeida@id.uff.br \\ HÉLDER PIRES AMÂNCIO iD \\ Universidade Federal de Santa Catarina | Florianópolis, SC, Brasil \\ hpamancio@gmail.com
}

DOI 10.11606/issn.2316-9133.v30i2pe179215

Foi um dia lindo e intenso! Começou com uma manhã ensolarada e alegre, quando saímos da Casa de Estudante, na cidade de Maputo, rumo ao Bairro Patrice Lumumba, na Matola, com muitas expectativas. Sabíamos que queríamos conversar com mulheres que amarram suas crianças com capulanas, mas não sabíamos onde, nem como! Tínhamos para oferecer água e entusiasmo, perguntas e cliques. A escolha pelo bairro surgiu aleatoriamente. Encontramos uma pracinha arborizada, conseguimos um pneu e uma cadeira emprestada com feirantes locais. Mateus Almeida com seu sorriso e sua câmera, Hélder Pires Amâncio com sua moçambicanidade e seu changana, Vera Gasparetto com sua feminilidade e empatia. Assim, tentamos estabelecer contato com as mulheres jovens que passavam pela via pública.

A nossa química encontrou-se com oito mulheres e suas lindas crianças. Foi um furacão de energia que, em 3 horas, possibilitou-nos realizar contatos além do que esperávamos. Passamos o dia inteiro, conversando com as mulheres que se dispuseram. À tarde fez muito calor e no final do dia, a temperatura mudou repentinamente, céu nublado e alguns pingos que logo transformaram-se em uma chuva torrencial que intercalava e, por vezes, simultaneamente vinha cheia de raios e estrondosas trovoadas. Encerramos o dia que começou brilhante de sol com 
tempestade. A brusca mudança do dia traduzia muito bem, em nosso entender, o nosso estado emocional agitado e tomado pela alegria. Voltamos para casa felizes, com o sol que novamente voltava a brilhar, entendendo que recebemos 17 presentes nas nossas vidas: as imagens e as lindas histórias dessas mulheres e crianças, que passaram a fazer parte da nossa caminhada, da nossa compreensão e do nosso retorno, mas acima de tudo desse "corredor de saberes" entre Brasil e Moçambique/África (Gasparetto, 2019).

Buscamos por mulheres que andavam pelas ruas com seus bebês amarrados nas capulana, tarefa aparentemente fácil, pois são muitas, mas mostrou-se desafiadora, nem todas se animaram de conversar conosco pela desconfiança. O que nos motivou foi entender as dinâmicas que fazem com que as crianças estejam juntas a quem lhe cuida o tempo inteiro: em casa, pelas ruas, sob o sol, nos mercados, no trabalho informal. A tranquilidade de pequeninas e pequeninos chamounos a atenção! Interessava-nos saber destas mulheres o significado que têm a capulana para elas e através daquela as histórias das próprias mulheres e sua relação com as crianças. As narrativas e imagens abaixo documentam essas relações. Selecionamos alguns fragmentos relativos a cuidados, relações mãe-filho e relações com a capulana.

Tendo como ponto de partida as relações e histórias desencadeadas pela capulana (Arnfred e Meneses, 2018), conversamos com Carolina Abú Ussemane, de 20 anos, que parou de estudar quando engravidou, para cuidar do filho Abu, que na altura, em 2017, tinha dois anos. Os projetos para o futuro de Carolina, incluem os estudos, formar-se, arranjar um emprego e trabalhar para cuidar do menino. Assim, ela compartilhou conosco um pouco da sua história de transição ao tornar-se mãe e o que ela chamou de uma "mulher responsável":

É uma fase, são duas coisas diferentes: quando eu era jovem, uma menina, e agora que sou mãe. Depois de ter engravidado eu fui crescendo e minha mentalidade mudou, pensando no futuro do meu filho e no meu. Após o parto e tudo mais, êpah, me tornei uma mulher responsável. Eu disse: 'Olha se minha mãe conseguiu, me carregar por nove meses, me pariu, cuidou de mim até nessa idade onde estou, por que não posso fazer o mesmo com meu filho?' Eu passei de uma fase muito difícil, que poderia ter levado a jogar meu filho na rua, doado ou mesmo vendido, pois o pai não quis assumir a responsabilidade. Então o tempo passou, as mágoas foram se curando e pensei "o caminho é para frente" (Carolina Abú Ussemane, 2017).

Na sequência, conversamos e fotografamos Claudia Mbebe, e seu filho Adriel, então com seis meses. Ela trabalha como recepcionista e supervisora em um hotel, dividindo seu tempo entre a difícil tarefa de ser mãe de duas crianças, esposa, gerir as tarefas domésticas e profissionais, contando com a ajuda de uma babá. Para Claudia a capulana tem um grande valor. 
Ao mesmo tempo que é, segundo ela, muito moderno usá-la para muitas coisas (sobretudo roupas), ela possui igualmente um valor tradicional (amarrar o bebê, usar em cerimônias, etc.). De acordo com Claudia:

Esse conhecimento de trazer o bebê junto a si no dia-a-dia, em alguns momentos facilita, porque dependendo da situação de cada família. [...] É muito mais fácil, por exemplo, quando não tenho outras pessoas ao meu redor para ajudar, levar o bebê no colo. Não que com isso ele não corra riscos, mas se torna mais fácil, por que se depender dele dormir, ou estar quieto, posso ficar todo dia com ele. É muito mais prático ter o bebê no colo para desembaraçar os afazeres. É bem ágil a capulana (Claudia Mbebe, 2017).

Enquanto isso, Ána Daniel Dzimba se aproximava de nós, acompanhou a conversa e pediu para a fotografarmos com suas filhas Vânia (nove meses) e Cayana (cinco anos). Ela tem 33 anos e vive com o marido e suas quatro meninas no Bairro Singathela, é dona-de-casa e vende roupas de "calamidade"1 para sustentar a família. Segundo Ána:

Esse hábito de amarrar assim a bebê é antigo, de nossos pais, bisavós, nossas mães. A Cayana tem 5 anos e também foi cuidada assim. A vantagem da capulana é que é mais segura é prática, pois quando estamos fazendo os trabalhos de casa e a bebê está a chorar, podemos nenecar ${ }^{2}$ e continuar as atividades. A capulana é mais usada agora para vestidos, saias, amarrar e outras coisas, e eu gosto muito de amarrar, trabalhar e fazer o serviço de casa. Aprendi assim mesmo, também sendo cuidada pela minha mãe com a capulana (Ána Daniel Dzimba, 2017).

Etelvina Zibia, de 21 anos, foi outra das nossas interlocutoras. Interpelamos Etelvina enquanto passeava com o filho Clarck, de seis meses. Segundo ela, seguia em direção à casa de uma amiga, onde ia trançar os cabelos. Para ela a experiência de ser mãe é muito boa e a capulana faz parte da constituição dessa mesma experiência. Ao explicar-nos sobre as diversas utilidades do pano, Etelvina destaca os diferentes usos e significados especiais que o tecido denominado capulana em Moçambique pode assumir no cotidiano, quando se usa para criança, quando é uma capulana ofertada, capulana comprada para o uso pessoal etc.:

\footnotetext{
${ }^{1}$ No Brasil é conhecido como brechó.

${ }^{2}$ É uma expressão comum usada em Moçambique para se referir a levar a criança no colo, amarrada com o auxílio de uma capulana.
} 
Nós usamos muito a capulana para nenecar e tapar o bebê, e usamos para nós mesmas, fazemos vestidos e muita coisa. É uma tradição moçambicana, pois a capulana é segura. [...] Nós temos capulana especial para amarrar as crianças. Tenho essa que amarrei, que minha mãe ofereceu, e outra que está em casa. Capulana de bebê é só capulana de bebê. Minha capulana tem que ser só minha, não posso usar a mesma para ele, pois não faz bem. Segundo meus avós, dizem que quando eu amarro a capulana de bebê e depois amarro o bebê, há de sair feridas, então não posso fazer isso. Eu uso a minha capulana e ele a dele (Etelvina Zibia, 2017).

Flórda Zandamul, de 20 anos, foi nossa interlocutora. Ela é estudante e mãe da Wanga Cumbe, de cinco meses. Flórda, frequentava até a data da conversa o segundo ano do Curso Superior em Saúde, no Instituto Politécnico de Tecnologias e Empreendedorismo (IPESC), em Maputo. Sonha, para o seu futuro e da sua filha, em terminar o curso, graduar, ter um bom emprego e trabalhar. Sobre a sua experiência como mãe e a relação com a capulana, ela narra:

Estou muito contente de ser mãe, pois era seu sonho e calhou bem. O hábito de amarrar a capulana é porque os bebês se sentem mais seguros. As mães também. Nos sentimos mais seguras quando colocamos o bebê no colo com a capulana para fazer as atividades no dia a dia. No meu caso cozinho, lavo, carrego água, vou ao mercado. Só não faço os trabalhos escolares com ela porque é muito bagunceira (risos). É complicado, porque ela é um pouco chata, só quer a mãe, mas cuido dela com a ajuda da minha mãe (avó da criança), meu pai, meu marido (quando ele vem me visitar). Eu acho que amarrar a bebê com a capulana é legal né? É bonito, eu gosto de ver, não sou muito adepta à neneca pronta ${ }^{3}$, prefiro mais a capulana (Flórda Zandamul, 2017).

Ricardina Gércia Sitole, outra interlocutora, é mãe do bebê de dois meses, Ethon de Jesus. Ela vive com seu esposo e sua irmã e considera a experiência de ser mãe tão jovem muito boa, uma coisa única. "A gente ficava com medo antes, como vou atender, como vai ser, mas agora quando estou sozinha em casa já consigo rir e brincar, me expresso, é uma boa sensação”. Explica-nos que:

\footnotetext{
3 No Brasil é chamado de bebê conforto.
} 
Isso de amarrar os bebês nas capulanas vem de gerações. A gente faz isso pelos avós, pais, acaba copiando o que já vem de muito tempo para continuar a cuidar da criança do mesmo jeito, que a capulana a gente amarra forte e sente que a criança está bem. Já vem de muito tempo mesmo, eu mesmo fui cuidada assim. [...] a capulana protege a criança, é algo leve, suave, mais fácil. Faço com o filho amarrado nela os trabalhos domésticos (varro o quintal, lavo a loiça, lavar a roupa, limpezas). Quando ele está adoentado, faz diferença ele ficar mais junto. Se a gente vê que não está bem, pegamos a capulana, enrolamos o bebê e nos sentimos mais próximas a ele (Ricardina Gércia Sitole, 2017).

Mais duas narrativas seguem. A de Maria João de Araújo, que leva o seu filho Cheron, de 1 ano e dois meses para todas as atividades do seu cotidiano Ela tem 6 filhos e todas suas crianças, segundo ela, foram amarrados na capulana. Ela é vendedora e gueva legumes no Mercado Grossista do Zimpeto, de segunda a sábado, e o bebê a acompanha em todos os momentos. Sobre o costume de amarrar a capulana, ela diz:

Esse costume é a nossa tradição aqui, a tradição moçambicana (risos). Ela vem da raiz, nossas mães nos nenecavam com capulanas. Para deixar em casa [o bebê] (risos), é complicado. Eu fico a pensar se está a chorar, ora com as outras irmãs, eu prefiro levar. Quando está doente não vou guevar, levo no hospital, medico a criança até melhorar e daí retorno às minhas atividades. Na minha família todas as pessoas usam muito a capulana. Eu até que gosto muito da capulana, amarro na cintura, uso na cabeça. E com o bebê na capulana amarrada fica mais seguro. Eu recomendaria às mulheres brasileira (risos) que se habituassem a nenecar os bebês nas capulanas, pois acho que usam mais o bebê conforto. [...] a capulana é mais bonita para nenecar bebê. Ele não sente nenhum desconforto, sempre junto à mamã (Maria João de Araújo, 2017).

Nossa última conversa foi Lina Carla Mauro, de 21 anos, mãe de Kaylane, de quatro meses. Ela queria muito que conhecêssemos sua filha e nos convidou para ir à sua casa, onde vive com a mãe e três irmãos. Ela gosta muito de sua profissão de cabeleireira e atende as pessoas na sua casa ou em domicílio. Ela conta que só alguns homens usam a capulana para nenecar bebê, "mas não é do costume, eles usam os panos para fazer camisas e calças". Em sua perspectiva, explica:

\footnotetext{
${ }^{4}$ Gueva significa comprar no atacado para revender no varejo.
} 
Eu acho que é por causa da nossa cultura, usamos capulana para amarrar e nenecar, dando mais conforto ao bebê. Nós nascemos a saber que tem que usar a capulana para nenecar o bebê. Além de trançar, amarro a bebê para varrer o quintal e dentro, lavar a louça, cozinhar [começa a chover fazendo muito barulho sobre o teto de zinco]. Nosso costume é ter uma capulana só para nenecar o bebê para evitar bactérias e certas doenças, por que não posso usar a mesma capulana para mim ou para emprestar a alguém. Para evitar contaminar a pele do bebê usamos uma única capulana. Essa que ela está é especial, quem ofereceu foi a madrinha dela. Usamos a capulana para demonstrar o amor, o carinho que temos com a nossa filha, vê só, fica bonito, ela sente o amor, aprende a crescer com a mãe e a valorizar mais, é pra isso que a capulana ajuda (Lina Carla Mauro, 2017).

Fica evidente nas várias narrativas o valor do cuidado e afeto que a capulana assume, além da sua praticidade no dia a dia (Arnfred e Meneses, 2018). O projeto que realizamos com o apoio de pesquisa da CAPES, traz em imagens e palavras a vida de mulheres moçambicanas comuns, que não têm espaço na história oficial de Moçambique. O olhar dessas mulheres está entrelaçado com a história da capulana e das crianças/infâncias no contexto moçambicano e, portanto, do cuidado que as mulheres têm com as famílias, com bebês, mas também, traz suas lutas e resistências cotidianas. Esse trabalho nos permitiu conhecer um pouco da realidade dessas mulheres e suas percepções sobre a maternidade, suas dificuldades e alegrias, dores e aprendizados, desafios e respeito, entrelaçadas pelas capulanas.

\section{Referências bibliográficas}

ARNFRED, Signe; MENEZES, Maria Paula. 2018. "Mozambican Capulanas: Tracing Histories and Memories". In: KHAN, Sheila Pereira; MENESES, Maria Paula; BERTELSEN, Bjørn Enge. Mozambique on the move: Challenges and Reflections. Londres: Brill, pp. 186-210. DOI 10.1163/9789004381100_011

GASPARETTO, Vera; ALMEIDA, Mateus; AMÂNCIO, Hélder Pires. 2017. Mamãs, Bebês e Capulanas: cuidados e afetos tecidos nos corpos. Projeto Editorial e Fotográfico, 2017. (Mimeo).

GASPARETTO, Vera F. 2019. Corredor de Saberes: vavasati vatinhenha (mulheres heroínas) e redes de mulheres e feministas em Moçambique. Florianópolis, Tese de Doutorado, Universidade Federal de Santa Catarina. 


\section{Entrevistas}

ARAÚJO, Maria João de. Bairro Patrice Mulumba [12 out. 2017]. Entrevistadora: (VG). Matola - Moçambique, 2017. Entrevista para o Projeto Mamãs, Bebés e Capulanas: cuidados e afetos tecidos nos corpos. Transcrição: (VG).

DZIMBA, Ána Daniel. Bairro Patrice Mulumba [12 out. 2017]. Entrevistadora: Vera Gasparetto (VG). Matola - Moçambique, 2017. Entrevista para o Projeto Mamãs, Bebés e Capulanas: cuidados e afetos tecidos nos corpos. Transcrição: (VG).

MAURO, Lina Carla. Bairro Patrice Mulumba [12 out. 2017]. Entrevistadora: (VG). Matola Moçambique, 2017. Entrevista para o Projeto Mamãs, Bebés e Capulanas: cuidados e afetos tecidos nos corpos. Transcrição: (VG).

MBEBE, Claudia. Bairro Patrice Mulumba [12 out. 2017]. Entrevistadora: (VG). Matola Moçambique, 2017. Entrevista para o Projeto Mamãs, Bebés e Capulanas: cuidados e afetos tecidos nos corpos. Transcrição: (VG).

SITOLE, Ricardina Gércia. Bairro Patrice Mulumba [12 out. 2017]. Entrevistadora: (VG). Matola - Moçambique, 2017. Entrevista para o Projeto Mamãs, Bebés e Capulanas: cuidados e afetos tecidos nos corpos. Transcrição: (VG).

USSEMANE, Carolina Abú. Bairro Patrice Mulumba [12 out. 2017]. Entrevistadora: (VG). Matola - Moçambique, 2017. Entrevista para o Projeto Mamãs, Bebés e Capulanas: cuidados e afetos tecidos nos corpos. Transcrição: (VG).

ZANDAMUL, Flórda. Bairro Patrice Mulumba [12 out. 2017]. Entrevistadora: (VG). Matola Moçambique, 2017. Entrevista para o Projeto Mamãs, Bebés e Capulanas: cuidados e afetos tecidos nos corpos. Transcrição: (VG).

ZIBIA, Etelvina. Bairro Patrice Mulumba [12 out. 2017]. Entrevistadora: (VG). Matola Moçambique, 2017. Entrevista para o Projeto Mamãs, Bebés e Capulanas: cuidados e afetos tecidos nos corpos. Transcrição: (VG).

\section{sobre autora e autores}

Vera Gasparetto

Pós-Doutoranda no Programa de Pós-Graduação Interdisciplinar em Ciências Humanas na Universidade Federal da Santa Catarina, pesquisadora do Laboratório de Estudos de Gênero e História e do Instituto de Estudos de Gênero. É pesquisadora do Centro de Estudos Africanos (CEA) e professora colaboradora no Mestrado em Gênero e Desenvolvimento, ambos na Universidade Eduardo Mondlane (UEM) em Moçambique. 


\section{Mateus Almeida}

Fotógrafo, graduado em Licenciatura em Ciências Sociais pela Universidade Federal Fluminense (UFF) com período sanduíche na Universidade Eduardo Mondlane (UEMMoçambique). Pesquisador vinculado ao Laboratório de estudos sobre movimentos sociais, trabalho e identidade (LEMSTI) e Pesquisador Assistente do Núcleo Afro do Centro Brasileiro de Análise e Planejamento.

\section{Hélder Pires Amâncio}

Doutor e Mestre em Antropologia Social pela Universidade Federal de Santa Catarina, com graduação em Antropologia pela Universidade Eduardo Mondlane (UEM), em Moçambique. É professor de Antropologia na UEM e na Universidade Wutive (UNITIVA).

Contribuição de Autoria: Não se Aplica Financiamento: CAPES.

Recebido em 08/12/2020

Aceito para publicação em 01/06/2021 


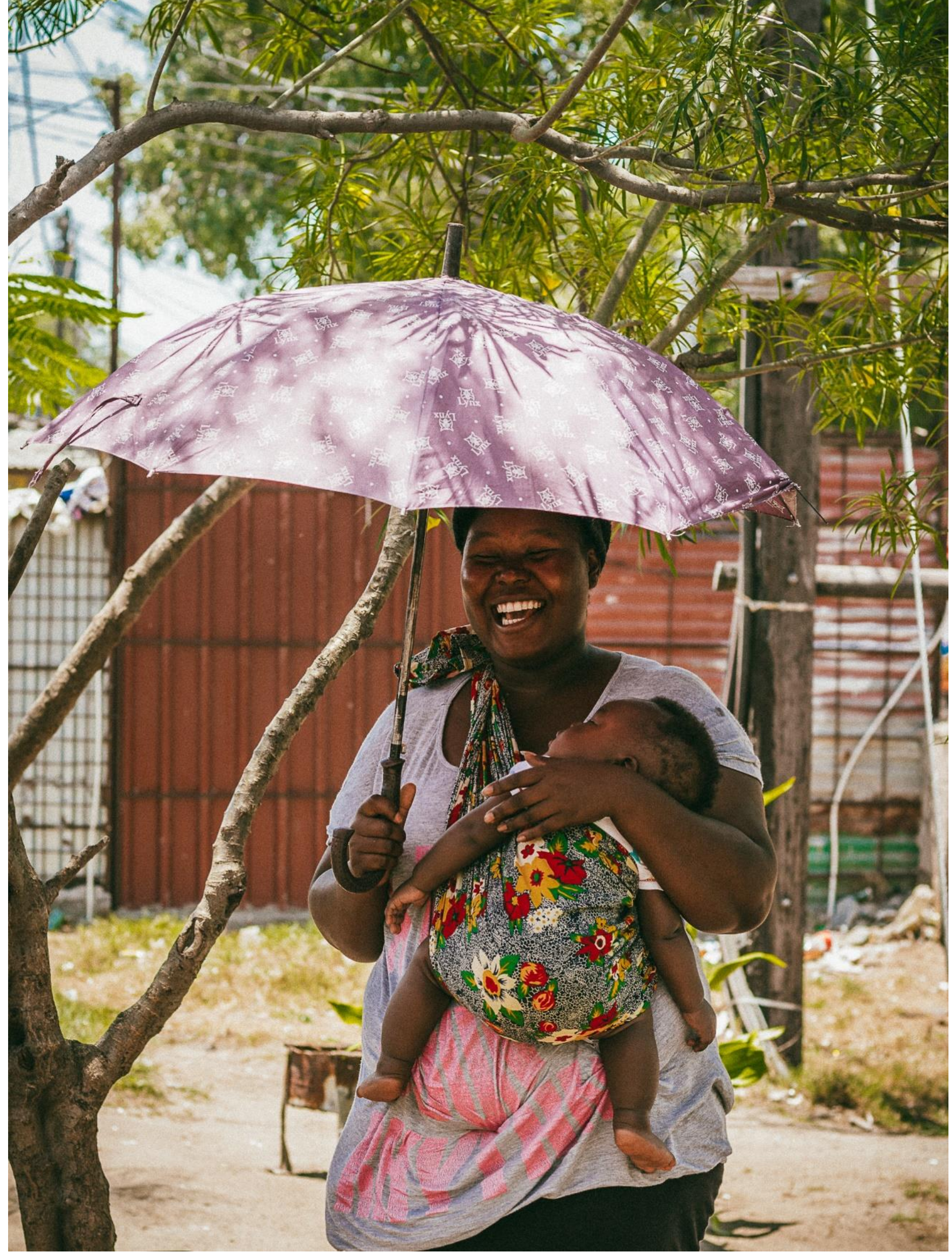

Figura 1. Etelvina Zibia cultiva a tradição de utilizar uma capulana especial para amarrar seu bebê Clarck, de 6 meses (2017). 


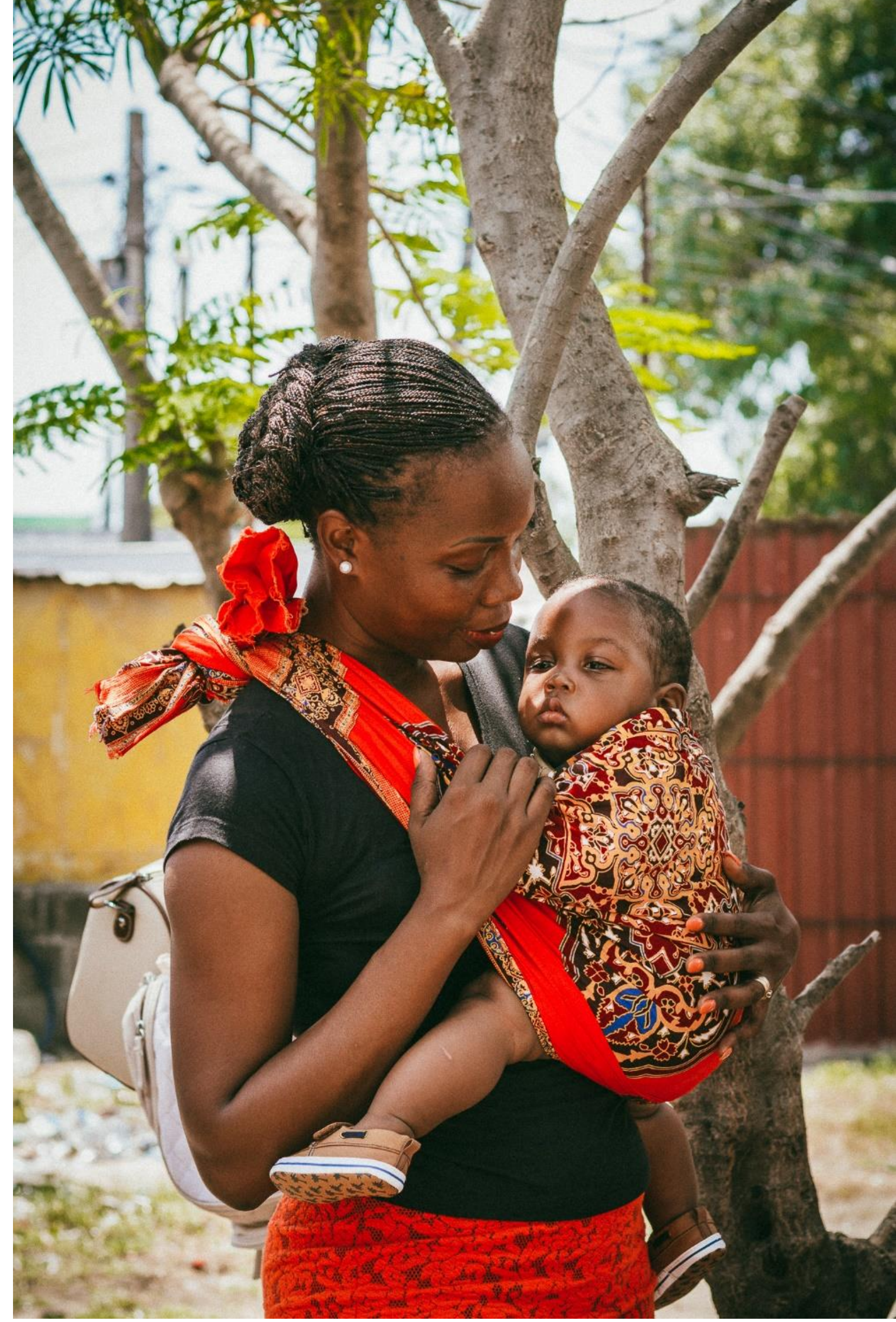

Figura 2. A profissional de turismo, Claudia Mbebe leva o bebê Adriel (6 meses) junto a si, pois a "capulana está no sangue" (2017). 


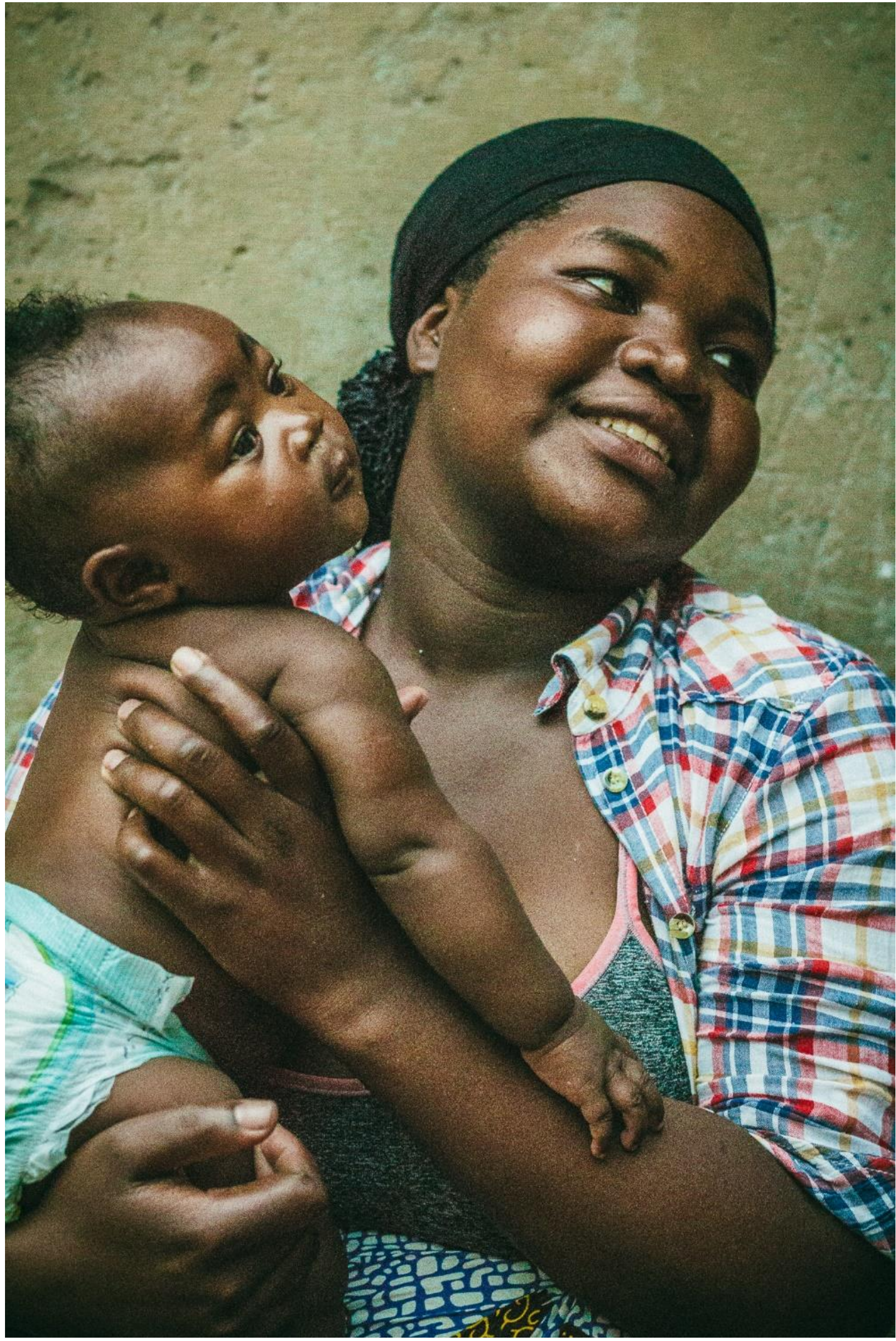

Figura 3. A cabelereira Lina Carla Mauro cuida da filha Kaylane ( 4 meses) com a capulana "para ela sentir amor" (2017) 


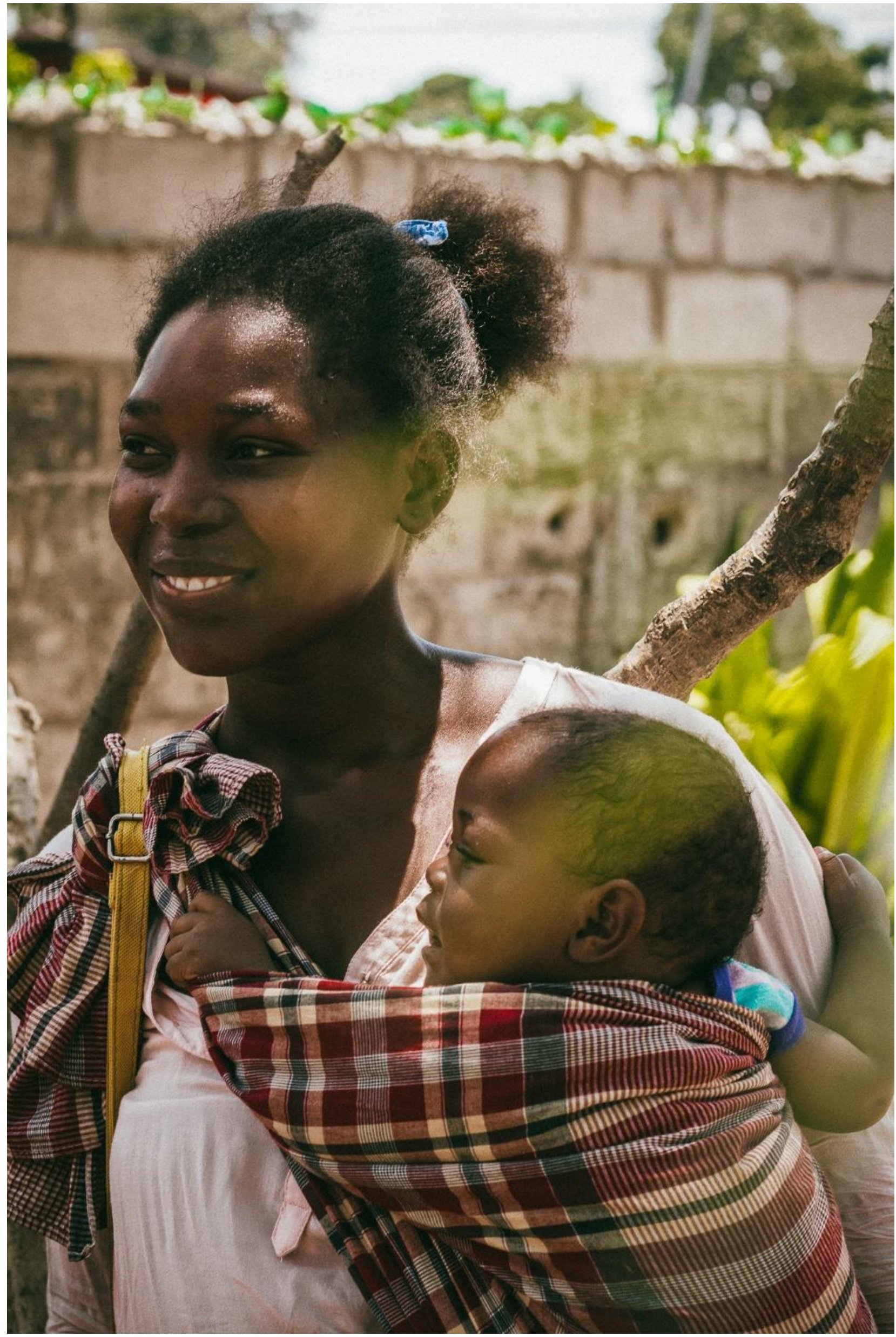

Figura 5. Ána Daniel Dzimba traz junto a si a bebê Vânia ( 9 meses) por ser mais seguro enquanto realiza suas atividades de vendedora (2017). 


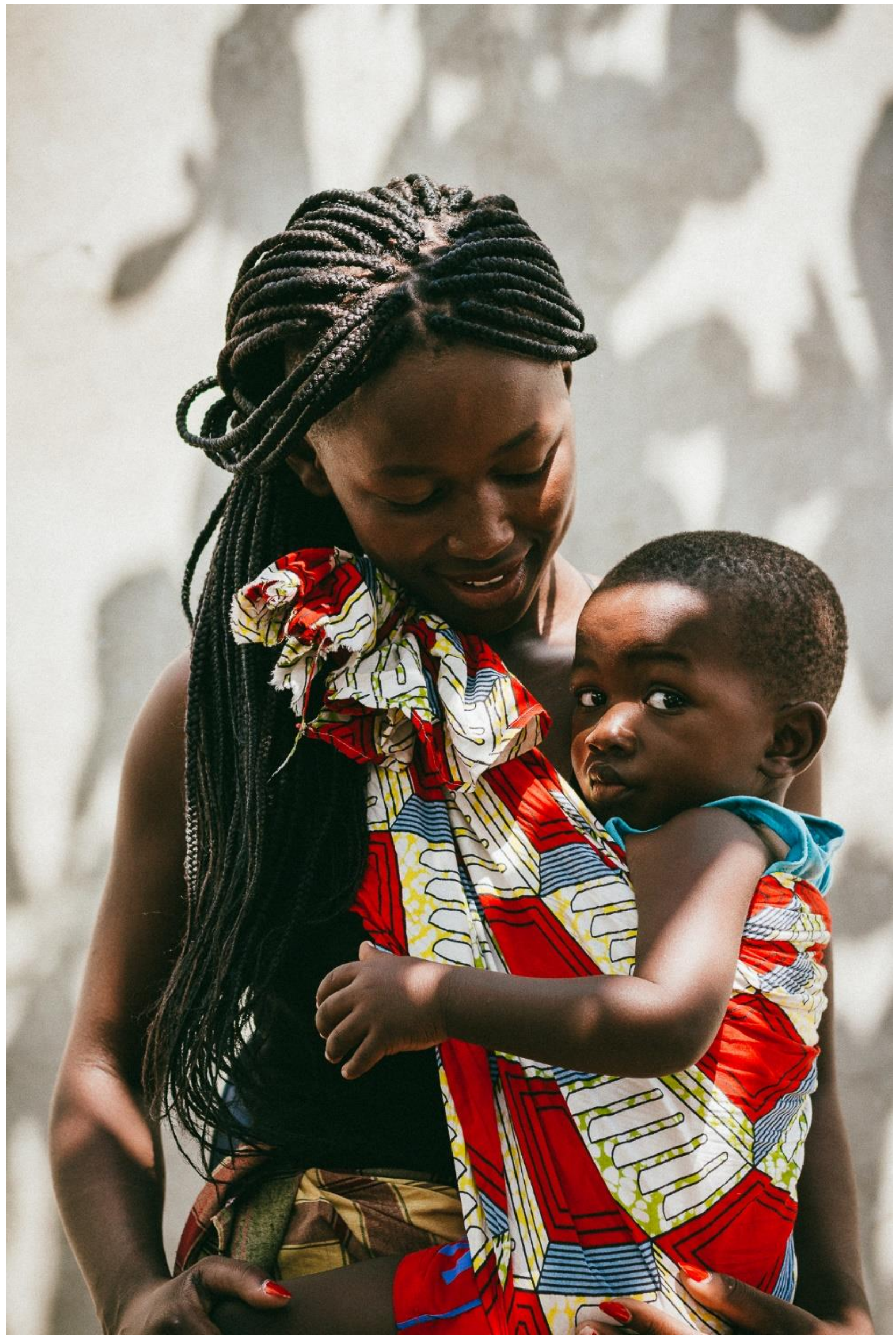

Figura 6. A jovem Carolina Ussemane amarra o filho Abu (2 anos) para realizar suas atividades cotidianas (2017) 


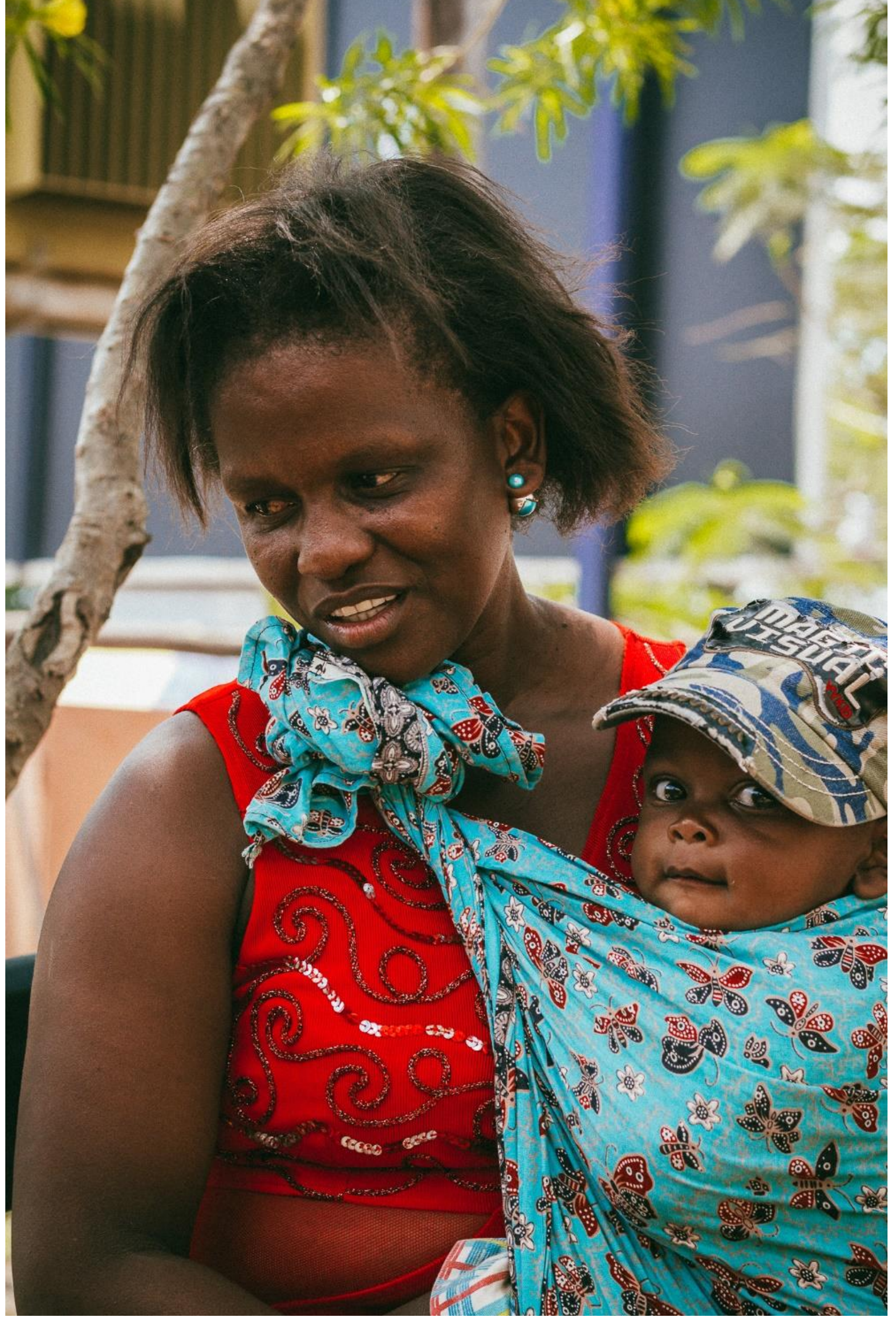

Figura 8. Maria João de Araújo usa a capulana para levar o menino Cheron (1,2 ano) enquanto vende legumes no mercado: "é das raízes das nossas mães" (2017). 